\title{
The Pathogenesis of Hyperuricemia in Glycogen Storage Disease, Type I
}

\author{
THOMAS F. ROI:H: AND MAURICE D). KOGUT \\ Division of Lindocrinology and Metabolism, Children's Hospital of Los Angeles, and the Dopartment of Pediatrics, \\ University of Southern California, School of Wedicine, Los Angeles, California, USA
}

\section{Summary}

After the infusion of fructose, $0.25 \mathrm{~g} / \mathrm{kg}$ body weight, blood uric acid levels were significantly increased above the mean basal value in five patients with glycogen storage disease (GSI)), type I $(P<0.02-P<0.05)$. The mean fasting blood inorganic phosphate (Pi) level in the patients was $3.9 \pm 0.3 \mathrm{mg} / 100 \mathrm{ml}$ and was significantly lower than the mean $P i$ value of $4.8 \pm 0.3 \mathrm{mg} /$ $100 \mathrm{ml}$ of the control subjects $(P<0.05)$. Blood Pi levels were significantly lower in the patients than in the control subjects at varying times after the administration of fructose $(P<0.005-P$ $<0.05)$. Uric acid excretion did not increase significantly in the patients after fructose was given.

In contrast to normal children, the mean peak blood uric level in the patients increased significantly after the administration of glucagon $(P<0.001)$. In both patients $(P<0.005)$ and control subjects $(P<0.05)$, mean blood $P i$ concentrations decreased significantly after the administration of glucagon; however, the blood Pi concentrations in the patients were significantly lower than in the control subjects. Uric acid excretion increased after glucagon administration in both patients and control subjects, but the differences in uric acid excretion between the two groups were not significant.

The data in our patients after fructose and glucagon administration suggest that hyperuricemia in GSD results from enhanced nucleotide catabolism. The concentrations of hepatic Pi and ATP may be low in patients with GSD; hepatic Pi and ATP content would therefore be further diminished by the administration of fructose and glucagon. By a mechanism similar to that of fructose-induced hyperuricemia, diminished hepatic $\mathrm{Pi}$ and ATP content might increase the breakdown of adenine nucleotides with resultant hyperuricemia.

\section{Speculation}

Decreased intrahepatic Pi and ATP content, which ultimately results in enhanced nucleotide catabolism, may be a common mechanism for hyperuricemia under variety of conditions.

Hyperuricemia, gout, and its complications occur frequently in patients with GSD type I $(1,12,23-25,27,29)$. Hyperuricemia results, in part, from decreased renal tubular secretion of urate secondary to lactic acidemia and ketonemia $(1,12,27)$ and from increased uric acid production $(1,27,29)$. The cause of urate hyperproduction is not known.

Recent observations suggest that enhanced nucleotide catabolism, as noted after fructose administration in normal subjects $(36,47)$ and in children with hereditary fructose intolerance (IIFI) $(31,36)$, may play an important role in increasing urate production in man. The mechanism of fructose-induced hyperuricemia has been attributed to the degradation of adenine nucleotides resulting from decreased hepatic content of inorganic phosphate (Pi) and adenosine triphosphate (ATP) $(4,34,38,49)$.

Accordingly, patients with GSD type I may have increased urate production from accelerated catabolism of purine nucleotides, which, in turn, results from decreased hepatic content of $\mathrm{Pi}$ and ATP. Hepatic Pi and ATP levels are diminished becase phosphorylated glycolytic intermediates have accumulated as a consequence of glueose-6-phosphatise deficiency. In the present report, data are presented which support the hypothesis that hyperuricemia in GSD type 1 results from increased breakdown of preformed hepatic purine nucleotides.

\section{MATERIALS AND METHODS}

The study group consisted of 10 patients, 7 males and 3 females, 3 4/12-28 years of age with GSD type 1; all patients hatd fasting hypoglycemia, hyperlacticalcidemia, hyperlipidemia, hyperuricemia, and marked hepatomegaly. Blood glueose levels did not increase after the administration of subcutaneous glucagon nor intravenous fructose (absent hepatic glucose-6-phosphatase activities were demonstrated in six patients, and four others were diagnosed only by clinical criteria). Six healthy children aged 2-153/12 years (31) in whom fructose tolerance tests were performed. and seven additional healthy children, aged $+6 / 12-$ $124 / 12$ years with nonendocrine growth retardation to whom glucigon was administered, were used as normal control subjects. All patients were admitted to the Clinical Research Center of the Childrens llospital of Los Angeles (CHLA) and were given a normal diet for age and size. The studies were approved by the Committee on Human Ixperimentation of CIL $A$, and informed patient and/or parental consent was obtained.

After an overnight fast. six healthy children and five patients with GSD received a fructose tolerance test as follows. Fructose, $0.25 \mathrm{~g} / \mathrm{kg}$ body weight, was administered intravenously in a $10 \mathrm{Co}$ solution over $3-5 \mathrm{~min}$. Blood levels of glucose, fructose, Pi, lactic acid, and uric acid were measured in the fasting state and at $10,20,30,40,50,60,80,100$, and $120 \mathrm{~min}$. In four normal children and in four patients with GSD urine was collected in two 4-hr periods, before and after fructose administration, for measurement of uric acid and creatinine.

On another day, after an overnight fast. glucagon, $1 \mathrm{mg}$, was administered subcutaneously to seven healthy children and to eight patients with GSD type 1. Blood levels of glucose, uric acid, lactic acid, and Pi were measured in the fasting state and at $30,45,60,90$, and $120 \mathrm{~min}$. In six normal children and in five patients with GSD, urine was collected in two 4-hr periods, before and after glucagon administration, for measurement of uric acid and creatinine. Pi was also measured in the urine in two normal children and in two patients with GSD.

De novo purine biosynthesis was studied in two patients with GSD by determining the incorporation of $10 \mu \mathrm{Ci}$ of intravenously administered $[U-14 \mathrm{C} \mid g l y c i n e$ in urinary uric acid $(50)$. The activity of hypoxanthine-guanine phosphoribosyltransferase (IGPRT) was measured in erythrocytes of the GSD patients by reacting " $\mathrm{C}$-labeled hypoxanthine with phosphoribosylpyrophosphate in the presence of the supernatant from hemolyzed erythrocytes and isolating the nucleotide (8). 
Blood glucose was measured by a glueose oxidase method 26), serum lactic acid was measured by the method of Barker ind Summerson (3), blood fructose by the method of Schreiner 42 ), and $\mathrm{Pi}$ by a modification of the Fiske and SubbaRow nethod (13). Plasma and urinary uric acid were determined by in enzymatic spectrophotometric method (37). Data were anayzed for statistical significance by using a two-tailed paired and unpaired Student's test (43).

\section{RESULTS}

\section{FRUCTOSE INFUSION}

Blood. The levels of blood uric acid, glucose, Pi, lactic acid, and fructose after the administration of fructose in five patients with GSD type $I$ and in six normal children are indicated in Figure 1.

The mean \pm SEM fasting blood uric acid level was $9.3 \pm 0.8$ $\mathrm{mg} / 100 \mathrm{ml}$ and significantly higher in the patients with GSD type than the mean uric acid value of $4.12 \pm 0.5 \mathrm{mg} / 100$ of normal shildren $(P<0.001)$. At all times following the administration of fructose, mean blood uric acid levels were significantly greater than the values in control children $(P<0.005)$. In the GSD patients, the mean blood uric acid levels were significantly inzreased above the mean basal value $10,20,30,60$, and 80 min after the infusion of fructose. In contrast, fructose did not elicit a significant increase in blood uric levels in control children. The mean fasting blood glucose concentration in the patients was

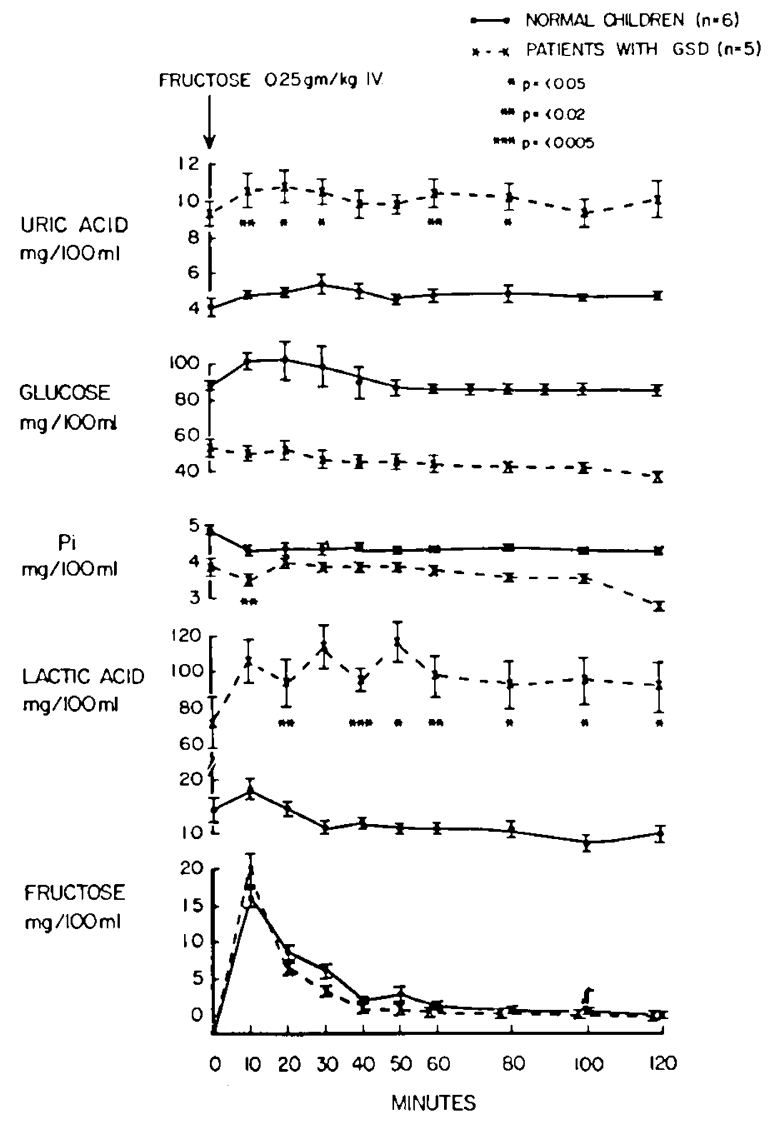

Fig. 1. Mean \pm SEM responses of blood uric acid, glucose, inorganic hosphate $(P i)$, lactic acid, and fructose in six normal children and in ive patients with glycogen storage disease $(G S D)$ type I after the ntravenous administration of fructose. The $P$ values indicate the signifiance of the differences between the mean resting $(0)$ values and the nean values at each time after fructose administration in the patients. for significance of the difference of the values between patients and hormal children see text. significantly lower than that of the control subjects $(P<0.001)$, and blood glucose levels did not increase after fructose. The mean fasting blood $\mathrm{Pi}$ level in the patients was $3.9 \pm 0.3 \mathrm{mg} / 100$ $\mathrm{ml}$ and significantly lower than the mean Pi value of $4.8 \pm 0.3$ $\mathrm{mg} / 100 \mathrm{ml}$ of the control subjects $(P<0.05)$. The mean blood Pi level in the patients was significantly less than the mean fasting level $10 \mathrm{~min}$ after fructose $(P<0.02)$, but this value was not different from that of the control subjects. In the patients, however, mean blood Pi levels were significantly lower than the values of the control subjects: $40(P<0.005), 50(P<0.05)$, $60(P<0.005), 80(P<0.01), 100(P<0.02)$, and $120(P<$ $0.02)$ min after the administration of fructose. The mean fasting blood lactic acid concentration in the patients was significantly higher than that of the control value $(P<0.005)$. After the infusion of fructose, the concentrations of lactic acid increased significantly in patients and in control subjects. However, the mean change $(\Delta)$ in lactic acid in the patients was $28.2 \pm 5.9 \mathrm{mg} /$ $100 \mathrm{ml}$ and higher than the slactic acid coneentration of $4.3 \pm$ $0.7 \mathrm{mg} / 100 \mathrm{ml}$ of the control subjects; elevated lactic acid levels persisted in the patients. The mean peak blood fructose level in the patients was similar to the mean peak level of normal children after fructose administration. The rate of fructose disappearance in the patients was similar to that of normal children.

Urine. Before fructose was administered, the mean uric acid excretion in four patients with GSD type 1 expressed as milligrams per $\mathrm{mg}$ urinary creatinine, was $1.5 \pm 0.6$, as compared with $0.6 \pm 0.1$ in normal children; the difference was not significant (Table 1). Although uric acid excretion increased in the patients after fructose was administered, the difference in uric acid excretion before and after fructose was not significant. In contrast, a significant increase in uric acid excretion in normal children occurred after fructose $(P<0.02)$.

\section{GLUCAGON ADMINISTRATION}

Blood. The levels of blood uric acid, glucose, Pi, and lactic acid after the administration of glucagon in seven normal children and in eight patients with GSD type $I$ are indicated in Figure 2.

Table 1. Excretion of uric acid $4 \mathrm{hr}$ before and after intravenous fructose, $0.25 \mathrm{~g} / \mathrm{kg}$, in normal children and in patients with glycogen storage disease (GSD) type I

\begin{tabular}{llc}
\hline & \multicolumn{2}{c}{ mg uric acid/mg creatinine } \\
\cline { 2 - 3 } \multicolumn{1}{c}{ Subjects } & \multicolumn{1}{c}{ Before } & After \\
\hline Normal' & & \\
$M L$ & 0.47 & 1.02 \\
$E L$ & 0.49 & 0.96 \\
$G C$ & 0.57 & 0.83 \\
$R K$ & 1.02 & 1.24 \\
Mean \pm SEM & $0.64 \pm 0.13^{2}$ & $1.01 \pm 0.08^{33}$ \\
& & $P<0.02^{4}$ \\
GSD Type I & & 0.8 \\
$T S$ & 0.7 & 0.5 \\
$K^{\prime} W$ & 0.4 & 2.7 \\
$G M$ & 2.5 & 3.5 \\
$R L$ & 2.5 & $1.88 \pm 0.73^{3}$ \\
Mean \pm SEM & $1.52 \pm 0.57^{2}$ & $P=\mathrm{NS}^{5}$
\end{tabular}

${ }^{1}$ Data from Kogut et al (31).

2 Patients versus normal children before the administration of fructose, $P=$ NS.

${ }^{3}$ Patients versus normal children after the administration of fructose, $P=$ NS

${ }^{4} P$ value refers to the difference between the mean values for urinary uric acid/creatinine before and after fructose in the normal children.

${ }^{5} P$ value refers to the difference between the mean value for urinary uric acid/creatinine before and after fructose in the patients with GSD). 


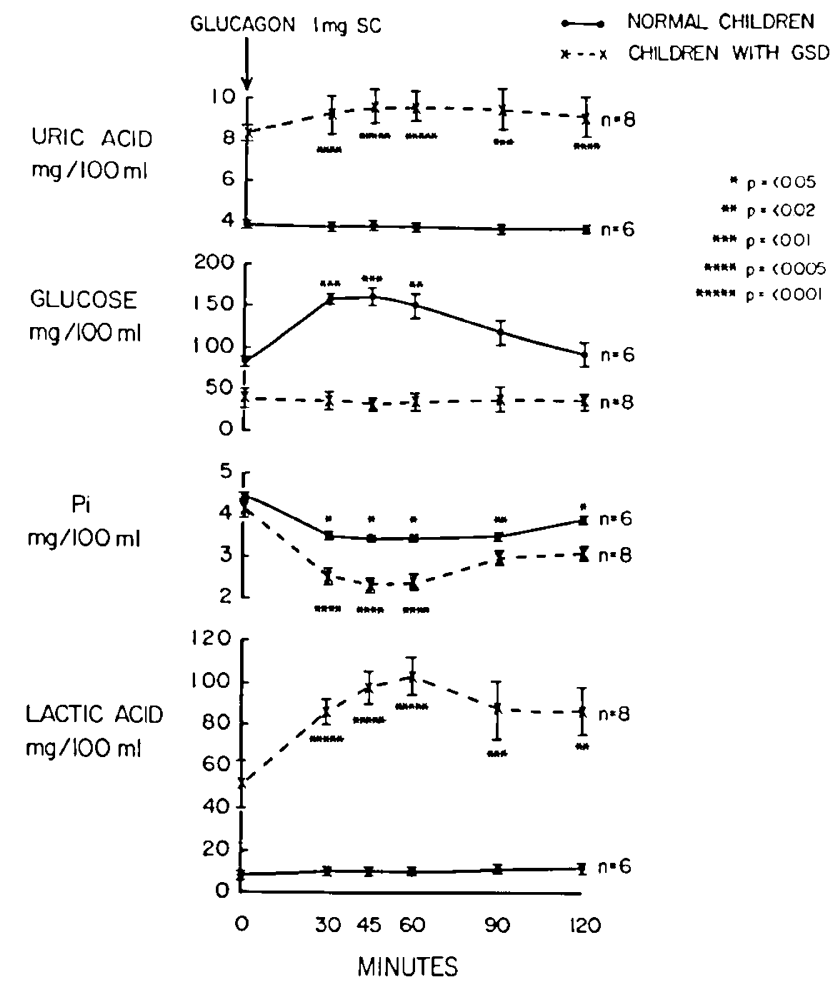

Fig. 2. Mean \pm SEM responses of blood uric acid, glucose, inorganic phosphate $(P i)$, and lactic acid in six normal children and in eight patients with glycogen storige disease $(G S D)$ type 1 after the subcutaneous administration of glucagon. The $P$ values indicate the significance of the differences between the mean resting (0) values and the mean values at each time after glucagon administration in both groups. For significance of the difference of the values between patients and normal children see text.

In the fasting state and at all times after the administration of glucagon, the mean blood uric acid levels in the patients were significantly higher than those in the control children $(P<$ $0.01)$. In contrast to the results in control children, the mean blood uric acid levels in the patients increased significantly after the administration of glucagon. Blood glucose concentrations did not rise after glucagon in the patients with GSD, in contrast to control children. Although the mean fasting blood Pi concentration in the patients was lower than in the control subjects, the difference was not significant. In both patients and control subjects, the mean blood Pi concentrations decreased significantly after the administration of glucagon. However, the mean blood $P i$ concentrations in the patients were significantly lower than those in the control subjects: $30(P<0.01), 45(P<0.005), 60$ $(P<0.01)$, and $120(P<0.05)$ min after the administration of glucagon. The mean blood lactic acid levels in the patients, both fasting and after glucagon, were significantly higher than in control subjects $(P<0.001)$. In contrast to the control subjects, the blood lactic acid levels increased significantly after the administration of glucagon in the patients with GSD.

Urine. The mean basal uric acid excretion in five patients with GSD, expressed as milligrams per $\mathrm{mg}$ urinary creatinine, was 1.2 \pm 0.5 and greater than the mean uric acid excretion of $0.8 \pm 0.1$ in six healthy children (Table 2); the difference was not significant. A significant increase in uric acid excretion occurred in normal children after glucagon $(P<0.02)$. After the administration of glucagon, the mean uric acid excretion in the patients increased 3-fold, but the difference in uric acid excretion before and after glucagon was not significant. After glucagon administration, Pi excretion doubled in one control subject and did not change in the other control or in two patients with GSD (Table 2).
Table 2. Excretion of uric acid and inorganic phosphate (Pi) in normal children and in patients with glycoge'n storage dise'ase (GSD) type I before and after administration of glucagon, I mg, subcutancously

\begin{tabular}{|c|c|c|c|c|}
\hline \multirow[b]{2}{*}{ Subjects } & \multicolumn{2}{|c|}{ mg uric acid/mg creatinine } & \multicolumn{2}{|c|}{$\begin{array}{c}m g \mathrm{Pi} / \mathrm{mg} \text { cre- } \\
\text { atinine }\end{array}$} \\
\hline & Before & After & $\begin{array}{l}\text { Be- } \\
\text { fore }\end{array}$ & After \\
\hline \multicolumn{5}{|l|}{ Normal } \\
\hline$D L$ & 1.0 & 1.7 & & \\
\hline$J D$ & 1.1 & 1.3 & 1.76 & 1.45 \\
\hline$A F$ & 0.9 & 1.5 & & \\
\hline$M L$ & 1.1 & 1.6 & 0.84 & 1.70 \\
\hline$C A$ & 0.8 & 2.1 & & \\
\hline$T W$ & 0.4 & 0.8 & & \\
\hline Mcan \pm SEM & \multicolumn{2}{|c|}{$P<0.02^{3}$} & & \\
\hline \multicolumn{5}{|l|}{ GSD Type I } \\
\hline$S V$ & 1.2 & 3.1 & & \\
\hline$K W$ & 0.3 & 0.6 & 0.62 & 0.61 \\
\hline TS & 0.6 & 1.9 & & \\
\hline$L G$ & 3.2 & 10.2 & & \\
\hline$G M$ & 0.9 & 2.2 & 1.57 & 1.60 \\
\hline Mean \pm SEM & $1.24 \pm 0.51^{1}$ & $\begin{array}{l}3.60 \pm 1.69^{2} \\
=\mathrm{NS}^{4}\end{array}$ & & \\
\hline
\end{tabular}

' Patients versus normal children before the administration of glucagon, $P=$ NS.

"Patients versus normal chikiten after the administration of glucagon, $P=$ NS.

${ }^{3} P$ value refers to the difference between the mean values for urinary uric acid/creatinine before and after glucagon in the normal children.

${ }^{+} P$ value refers to the difference between the mean values for urinary uric acid/creatinine before and after glucagon in the patients with GSD.

\section{INCORPORATION OF ISOTOPICALLY LABELED GLYCINE INTO URIC ACID}

The incorporation of precursor isotope into urinary uric acid during the 10 days after the intravenous administration of $[U$ ${ }^{14} \mathrm{C}$ lglycine in two patients with GSD is indicated in Figure 3. The cumulative recovery of isotope in urinary uric acid after the administration of glycine was increased as compared with control data reported by others $(32,45)$; the results are consistent with overproduction of uric acid. Normal incorporation is $0.1-0.15 \%$ of the injected dose after 7 days $(32,45)$.

\section{ASSAY OF HYPOXANTHINE-GUANINE PHOSPHORIBOSYLTRANSFERASE (HGPRT)}

The data obtained in the patients with GSD are shown in Table 3. All of the patients tested had normal erythrocyte HGPRT activity levels when hypoxanthine was utilized as substrate.

\section{DISCUSSION}

In untreated adolescents and young adults with GSD type 1 hyperuricemia and/or gouty arthritis are frequent occurrences $(1,12,23-25,27,29)$. Hyperuricemia was present in all our patients and one had had uric acid nephrolithiasis and hydronephrosis.

The abnormality in uric acid metabolism in patients with GSD type I appears to be related to decreased uric acid excretion (1, $12,27)$ and to urate hyperproduction $(1,27,29)$. The blood lactate and ketoacid levels which are higher than nomal in patients with GSD type $1(24,25)$ decrease the renal clearance of uric acid $(16,52)$, which results in increased blood uric acid concentration.

The results of these studies utilizing labeled glycine confirm the observation of others $(1,27,29)$ that patients with GSD type 


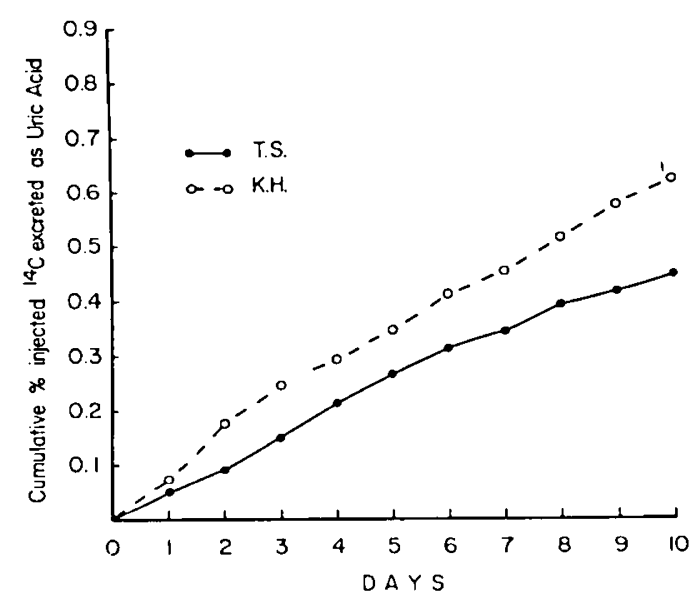

Fig. 3. Cummulative excretion of ${ }^{14} \mathrm{C}$ in urinary uric acid in two patients with glycogen storage disease type I following intravenous administration of $\left[U-{ }^{14} \mathrm{C}\right]$ glycine.

Table 3. Purine phosphoribosyl transferase activity in erythrocytes

\begin{tabular}{|c|c|}
\hline Subjects & $\begin{array}{c}\text { Hypoxanthine, } \mu \text { moles } / \mathrm{hr} / \mathrm{g} \\
\mathrm{Hb}\end{array}$ \\
\hline Controls $(n=21)$ & $106(78-136)^{1}$ \\
\hline \multicolumn{2}{|l|}{ GSD type I } \\
\hline$T S$ & 112.0 \\
\hline $\mathrm{KH}$ & 98.5 \\
\hline$V W$ & 73.0 \\
\hline$L G$ & 88.0 \\
\hline$J S$ & 110.0 \\
\hline$C B$ & 121.0 \\
\hline
\end{tabular}

' Mean activity, range of activities in parentheses.

1 have hyperuricenia because of increased urate production. Our findings in two patients with GSD indicate a modest increase in glycine incorporation into urinary urate.

The mechanism of urate hyperproduction in GSD is not known. Because deficiency or absence of HGPRT has been responsible for urate hyperproduction in children $(30,32)$, it is possible that a similar defect might exist in patients with GSD. As reported by others (29) and confirmed herein, however, normal erythrocyte HGPRT activities were found in patients with GSD.

It has been postulated (24) that in the absence of hepatic glucose-6-phosphatase, glucose-6-phosphate might be diverted into the hexose monophosphate shunt, causing an accumulation of phosphoribosylpyrophosphate (PRPP). Increased quantities of PRPP, the substrate for the first irreversible step in de novo purine biosynthesis, may augment purine synthesis, as postulated for urate hyperproduction in the Lesch-Nyhan syndrome $(14,20,41)$. Evidence against this hypothesis is the observation that the concentration of PRPP was normal in erythrocytes in patients with GSD (19). Because glucose-6-phosphatase is normally present only in liver, kidney, and small intestine (7), PRPP measurements in erythrocytes of patients with GSD type I are probably irrelevant; PRPP measurements in liver have not been reported in patients with GSD.

Recent observations that fructose may induce urate overproduction in normal individuals $(22,36)$ and in patients with HFI $(31,36)$ by enhancing nucleotide catabolism, led to the speculation that the pathogenesis of increased urate production in GSD type I may be similar. Hepatic ATP and Pi levels are diminished in animal and in normal human livers after the administration of fructose, which results in the degradation of adenosine monophosphate to inosinic monophosphate and subsequently to uric acid $(5,34,49)$. The results following the administration of fructose and glucagon in our patients strongly suggest that hyperuricemia in GSD type I results from diminished concentrations of hepatic Pi and ATP and the subsequent breakdown of adenine nucleotides.

After the intravenous administration of a small dose of fructose, unlike the responses of normal children and similar to those previously observed in patients with HFI (31), a modest but significant increase in blood uric acid levels accompanied by a significant decrease in blood $\mathrm{Pi}$ concentrations was noted in our patients with GSD. Hyperuricosuria did not accompany the rise in blood urate concentrations in the patients with GSD, however. This observation is different from that noted in patients with HFI, in whom a marked increase in uric acid excretion occurred after a similar dose of fructose (31). This difference in uric acid excretion may be due to the marked elevation of the blood lactic acid levels in patients with GSD after the administration of fructose.

The administration of glucagon increased the blood uric acid levels in our patients with GSD type I but not in the control subjects. In contrast to a previous report (1), glucagon also increased uric acid excretion in our patients despite marked elevations of blood lactic acid levels. An elevation in uric acid excretion without concomitant alterations in blood urate levels after glucagon administration has been noted in normal adults and in adults with gout (11), and is thought to result from a direct effect of glucagon on the renal tubule (11).

In our patients with GSD, blood Pi levels significantly decreased after glucagon. As confirmed in this study, a fall of the blood $\mathrm{Pi}$ concentrations after glucagon has also been noted in normal subjects $(6,10)$. The mechanism for glucagon-induced hypophosphatemia is not clear. The observations that glucagon has been shown to be phosphaturic in animals $(2,46)$ and in man (10), and that nephrectomy in rats abolishes most of the hypophosphatemic effects of glucagon (2), suggest that the kidneys have an important role in mediating the hypophosphatemic response to glucagon. A phosphaturic effect of glucagon was not noted in our patients, however. That the concentrations of blood $\mathrm{Pi}$ in our patients, both in the fasting state and after glucagon, were lower than control values, suggests another explanation for the hypophosphatemia in GSD.

The hepatic enzymatic defect in GSD may best explain the presence of hypophosphatemia which, in the fasting state, may have resulted from increased hepatic Pi uptake due to sequestration of $\mathrm{Pi}$ as phosphorylated glycolytic intermediates. The further decrease in blood $\mathrm{Pi}$ content following glucagon may have been enhanced by the process of glycogenolysis; because of the absence of glucose-6-phosphatase, hexose phosphates rather than glucose are produced as a result of glycogenolysis. Whether hepatic glucose-6-phosphate content is increased in patients with GSD type I is controversial. Values of hepatic glucose-6-phosphate 10 times above normal have been observed by Öckerman (35) in two patients with GSD type I. Although Hers (21) found normal levels of glucose-6-phosphate in other sections of liver from the same specimens used by Öckerman and from four other cases of GSD type I he did find an accumulation of this substance in two other liver biopsies of patients with type I.

Although the content of hepatic Pi and ATP has not been measured in patients with GSD, intracellular Pi depletion might also result in reduced formation of ATP. Erythrocyte ATP depletion has been noted in humans (33) and in dogs (51) during hypophosphatemia. Glycogenolysis after the administration of glucagon may have accentuated the decreased hepatic ATP content in our patients. In children with glucose-6-phosphatase deficiency (18), and under normal conditions (44), glucagon generates cyclic AMP in the liver (44); the phosphorylase system is activated and subsequently, glycogenolysis takes place (44). By this process ATP is consumed; ATP is required for generation of cyclic AMP and for activation of phosphorylase $(9,39)$.

Many metabolic disturbances in GSD, such as hyperlipidemia, ketonemia, hyperlacticacidemia, and hyperuricemia occur in response to hypoglycemia $(25,28)$; hyperuricemia has been re- 
versed after glucose administration in patients with GSD $(1,12)$. Because hypoglycemia normally results in increased glucagon secretion (15) and the administration of glucose suppresses glucagon secretion in normal individuals (48) and in patients with GSD type I $(17,40)$, variation in glucagon secretion may be one mechanism by which hyperuricemia is accentuated during hypoglycemia and improves with glueose administration in patients with GSD type I. It should be emphasized, however, that the elevation in blood uric acid levels in our patients occurred after pharmacologic doses of glucagon. Because blood uric acid concentrations did not increase in our normal subjects after the administration of fructose or glucagon, hepatic contents of $\mathrm{Pi}$ and ATP in GSD patients may be so critically low that even modest increases in endogenous glucagon secretion would enhance the breakdown of adenine nucleotides.

\section{CONCLUSION}

In patients with GSD type I, after the administration of intravenous fructose and subcutaneous glucagon, uric acid levels increased and Pi levels decreased in blood without significant increases in urinary uric acid excretion. In control children fructose and glucagon did not elicit an increase in blood uric acid levels, but significant increases in urinary uric acid excretion occurred. These results suggest that hyperuricemia in GSD results from enhanced nucleotide catabolism.

\section{REFERI:NCES AND NOTES}

1. Alepa, F. P., llowell, R. R., Klinenbery, J. R., and Secemiller, J. E. Relationships betseen glyengen storage disease and tophaceous gout. Amer. J. Med., 42: 58 (1967).

2. Aliapoulios, M. A., Morain, W. D., and Kacoyanis, G. P.: Glucagen as a hypocalemic and hypophosphatemic agent in the rat. Gastroenterology, 65: $912(1973)$.

3. Barker, S. B., and Summerson, W. H.: The colorimetric determination of lactic acid in biological material. J. Biol. Chem., 138: 535 (19+1).

4. Bode, J. C., Shumacher, H., Goebell, H., Zelder, O., and Pelzel, H.: Fructose induced depletion of liver adenine nucleotides in man. Hormone Metab. Res., 3: 289 (1971).

5. Bode, J. C., Zelder, O., Rumpelt, H. J., and Wittkamp, U.: Depletion of liver adenosine phosphates and metabolic effects of intravenous infusion of fructose or sorbitol in man and in the rat. Eur. J. Clin. Invest., 3: 436,1973

6. Bondy, P. K., and Cardillo, L. R.: The effect of glucagon on carbohydrate metabolism in norma! human beings. J. Clin. Invest., 35: 494 (1956)

7. Brown, B. I., and Brown, D. HI.: Glycogen-storage diseases: Types I, III, IV, V, VII and unclassified glycogenoses. In: Carbohydrate Metabolism and its Disorders, Vol. Il, p. 123 (Academic Press, New York, 1968).

8. Carticr, P., and Hamet, M.: Les activités purine-phosphoribosyl transférasiques des globules rouges humains: Technique de dosage. Clin. Chim. Acta, 20: 205 (1968).

9. Delange, R. J., Kemp, R. G., Riteg, W. D., Cooper, R. A., and Kress, F. G.: Activation of skeletal muscle phosphorylase and kinase by adenosine triphosphate and adenosine $3^{\prime}, 5^{\prime}$-monophosphate. J. Biol. Chem., 243: $2200(1968)$.

10. Elrick, H., Huffman, E. R., Hlad, C. J., Whipple, N., and Staub, A.: Heffects of glucagon on renal function in man. J. Clin. Endocrinol. Metab., 18: 813 (1958).

11. Elrick, HI., Whipple, N., Arai, Y., and Illad, C. J.: Further studies on the renal action of glucagon. J. Clin. Endocrinol. Metab., 19: 1274 (1959).

12. Fine, R. N., Strauss, J., and Donnell, G. N.: Hyperuricemia in glycogenstorage disease, type I. Amer. J. Dis. Child., 112: 572 (1966).

13. Fiske, C. H., and Subbakow, Y.: The colorimetric determination of phesphorus. J. Biol. Chem., 66: 375 (1925).

14. Fox, 1. H., and Kelley, W. N.: Phosphoribosylpyrophosphate in man: Birchemical and clinical significance. Ann. Intern. Med., 74: 424 (1971).

15. Gerich, J. E., Langlois, M., Noacco, C., Karam, J. H., and Forsham, P. H.: Lack of glucagon response to hypoglycemia in diabetes: Evidence for an intrinsic pancreatic alpha cell defect. Science, 182: 171 (1973)

16. Goldfinger, S., Klinenberg, J. R., and Seegmiller, J. E.: Renal retention of uric acid induced by infusion of heta-hydroxybutyrate and acetoacetate. New Engl. J. Med., 272: 351 (1965).

17. Gotlin, R. W., Block, M. B., Greene, H. L., Putman. C. W., and Starzl, T. E.: Metabolic influence of porto-caval anastomosis (PCA) in type I glycogen storage discase (GSD) [Abstr.]. Clin. Res., 22: 234A (1974).

18. Greene, H. L., Taunton, O. D., Stifel, F. B., and Herman, R. 1I.: The rapid changes of hepatic glycolytic enzymes and fructose-1,6-diphosphatase activitjes after intravenous glucagon in humans. J. Clin. Invest., 53: 44 (1974)

19. Greene, M. L., and Seegmiller, J. E.: Elevated erythrocyte phosphoribosylpyrophosphate in X-linked uric aciduria: Importance of PRPP concentration in the regulation of human purine biosynthesis. J. Clin. Invest., 48 : 32a $(1969)$.

20. Greene, M. L., and Seegmiller, J. E.: Erythrocyte 5-phosploribosyl-1-pyrophosphate (PRPP) in gout: Importance of PRPP in the regulation of human purine synthesis. Arthritis Rheum., 12: 666 (1969).

21. Hers, H. G.: Glycogen storage disease. In: Advances in Metabolic Diseases, Vol. 1, p. 1 (Academic Press, New York, 1964).

22. Heuckenkamp, P.-U., and Zöllner, N.: Fructose-induced hyperuricemia . Lancet, $i: 808(197 !)$.

23. Holling, H. E.: Gout and glycogen storage discase. Ann. Intern. Med., 58: $654(1963)$.

24. Howell, R. R.: The interrelationship of glycogen storage disease and gout. Arthritis Rheum., 8: 780 (1965)

25. Howell, R. R., Ashton, D. M., and Wyngaarden, J. B.: Glucose-6-phosphatase deficiency glycogen storage disease: Studies on the interrelationships of carbohydrate, lipid and purine abnormalities. Pediatrics, 29: 533 (1962).

26. Hugget, A. S. G., and Nixon, D. A.: Use of glucose oxidase, peroxidase and $\mathrm{O}$-dianisidine in determination of blood and urinary glucose. Lancet, ii: 368 (1957).

27. Jakovcic, S., and Sorensen, L. B.: Studies of uric acid metabolism in glycogen storage disease associated with gouty arthritis. Arthritis Rheum., 10: 129 $(1967)$.

28. Jeune, $\mathbf{M}$.: Sur certaines modifications biologisques et sur l'evolution lointaine de la polycorie glycogénique hepatique a propos de 9 observations. Miod. Prob. Pediat., 4: 209 (1959)

29. Kelley, W. N., Rosenbloom, F. N., Seegmiller, J. E., and Howell, R. R.: Excessive production of uric acid in type I glycogen storage disease. J. Pediat., 72: 488 (1968).

30. Kogut, M. D., Donnell, G. N., Nyhan, W. L... and Sweetman, 1..: Disorder of purine metabolism due to partial deficiency of hypoxanthine-guanine phosphoribosyltransferase: A study of a family. Amer. J. Med., 48: 148 (1970).

31. Kogut, M. D., Roe, T. F., Ng, W., and Donnell, G. N.: Fructose-induced hyperuricemia: Observations in normal children.and in patients with hereditary fructose intolerance and galactosemia. Pediat. Res., 9: 774 (1975).

32. L.esch, M., and Nyhan, W. L.: A familial disorder of uric acid metabolism and central nervous system function. Amer. J. Med., 36: 561 (1964).

33. Lichtman, M. A., Miller, D. R., and Freeman, R. B.: Erythrocyte adenosine triphosphate depletion during hypophosphatemia in uremic subject. New Engl. J. Med., 280: $240(1969)$.

34. Maenpiä, P. II., Raivio, K. O., and Kekomäki, M. P.: Liver adenine nucleor tides: Fructose-induced depletion and its effect on protein synthesis. Science, $161: 1253(1968)$.

35. Ockerman, P. A.: Phosphorylated glycolytic intermediates in liver and blood cells in members of a family with glycogenosis, type I. Clin. Chim. Acta, 8 ; 343 (196.3).

36. Perheentupa, J., and Raivio, K.: Fructose-induced hyperuricemia, Lancet, $i$ : $528(1967)$.

37. Praetorius, E.: An enzymatic method for the determination of uric acid $b$. ultraviolet spectrophotometry. Scand. J. Clin. Invest., l: 222 (1949).

38. Raivio, K. O., Kekomäki, M. P., and Maenpää, P. II.: Depletion of liver adenine nucleotides induced by D-fructose: Dose-dependence and specificity of the fructose effect. Biochem. Pharmacol., 18: 2615 (1969).

39. Rall, T. W., Sutherland, E. W., and Berthet, J.: The relationship of epinephrine and glucagon to liver phosphorylase. J. Biol. Chem., 224: 463 (1957)

40. Roe, T. F., and Kogut, M. D.: Chronic effects of oral glucose alimentation (GA) and protacaval shunt (PCS) in patients with glycogen storage disease (GSD), type I [Abstr.]. Pediat. Res., 10: 414 (1976).

41. Rosenbloom, F. M.: Biochemical bases of acelerated purine hiosynthesis de novo in human fibroblasts lacking hypoxanthine-guanine phosphoribosyltransferase. J. Biol. Chem., 243: 1166 (1968)

42. Schreiner, G. F.: Determination of insulin by means of tesorcinot. Proc. Soc. Exp. Biol. Med., 74: 117 (1950).

43. Snedecor, G. W., and Cochran, W. G.: Statistical Methods (kowa State University Press, Ames, Lowa, 1967).

44. Soderling, T. R., Hickenbottom, J. P., Reimann, I. M., Hunkeler, F. L., Walsh, D. A., and Krebs, E. G.: Inactivation of glycogen synthetase and activation of phosphorylase kinase by muscle adenosine $3^{\prime}, 5^{\prime}$-monophosphate-dependent protein kinase. J. Biol. Chem., 245: 6317, 1970.

45. Sorensen, L. B., and Benke, P. J.: Biochemical evidence for a distinct type of primary gout. Nature, 213: $1122(1967)$

46. Staub. A., Springs, V., Stoll, F., and Elrick, H.: A renal action of glucagon Proc. Soc. Exp. Biol. Med., 94: 57 (1957).

47. Stirpe, F., Dellacorte, E., Bonetti, E., Abbondanza, A., Abbati, A., and DeStefano, F.: Fructose-induced hyperuricemia. Lancet, ii: 1310 (1970).

48. Unger, R. H., Aguilar-Parada, E., Müller, W. A., and Eisentrout, A. M.: Studies of pancreatic alpha cell function in normal and diabetic subjects. J. Clin. Invest., 49: 837 (1970)

49. Woods, H. F., Eggleston, L. V., and Krebs, H. A.: The cause of hepatic accumulation of fructose-1-phosphate on fructose loading. Biochem. J., 119: $501(1970)$

50. Wyngaarden, J. B.: Normal glycine-C ${ }^{14}$-jncorporation into uric acid in primary gout. Metabolism, 7: 374 (1958).

51. Yawata, P., Craddock, R., Hebbel, R., Howe, R., Silvas, S., and Jacob, H.: Hyperalimentation hypophosphatemia: Hematologic-neurologic dysfunction due to ATP depletion. Clin. Res., 21: 729 (1973).

52. Yü, T. F., Sirota, J. H., Berger, L., Halpern, M., and Gutman, A. B.: I:ffect of sodium lactate on urate clearance in man. Proc. Soc. Exp. Biol. Med., 96: 809 (1957) 
53. The authors are grateful to the nurses of the Clinical Research Center for their invaluable assistance, to Dr. Won Ng. Division of Medical Genetics for measuring HGPRTase activity and incorporation of $\left[U-{ }^{14} \mathrm{C}\right]$ glycine into uric acid, to Ms. Betty Knoch and Ms. Carol Kanter for their expert technical assistance and to Mrs. Sue Platt for her secretarial help.

54. This research was supported in part by a grant from the General Clinical

Copyright (1) 1977 International Pediatric Research Foundtion, Inc.
Research Centers Program (RR-86) of the Division of Research Resources, National Institutes of Health.

55. Requests for reprints should be addressed to: T. Roc, M.D., P.O. Box 54700 , Terminal Annex, Los Angeles, Calif. 90054 (USA).

56. Received for publication Junc $21,1976$.

57. Accepted for publication October 1, 1976

Pediat. Res. 11: 669-676 (1977)

Enzymic differentiation

fetus

liver

\title{
Enzymic Differentiation of Human Liver: Comparison with the Rat Model
}

\author{
OLGA GREENGARD ${ }^{(70)}$ \\ Department of Biological Chemistry, Harvard Medical School, and the Cancer Research Institute, New England \\ Deaconess Hospital, Boston, Massachusetts, USA
}

\section{Summary}

The quantitative pattern of enzymes in the second trimester human fetal liver is significantly different from that of adult liver. For some 20 enzymes, the activity quotient $(\mathrm{AQ}$, i.e., activity of immature liver divided by that in adult liver) is appreciably different from 1.0. Most of the enzymes increase their concentrations with age but, as one would expect, some contribute to differentiation by diminishing in amount.

In developing human liver the concentrations of the various enzymes tend to change in the same direction as they do in rat liver. Those that increase in rat liver have been classified into three main clusters, according to whether their rise begins on about the 17 th day of gestation (B), the first neonatal day $(C)$, or just before weaning (D), respectively. The distribution of these enzymes among these three clusters correlates with their $A Q$ 's in the human fetal liver. In general, enzymes with $A Q$ around 0.5 belong to cluster $(B)$ in rat liver whereas those with $0-0.16$ belong to cluster $\mathrm{C}$ or $\mathrm{D}$.

Gross malformations resulting from the teratogenic action of drugs, hormones, or vitamins on the early embryo attract much attention. The harmful impacts of such agents at late stages of gestation are less spectacular. They may be more frequent, however, and manifest themselves in permanent inadequacies in metabolism or growth with a tendency to succumb to minor childhood diseases. The underlying causes may not be mirrored in the cytocomposition or even the subcellular morphology of autopsy specimens. Only deviations from the organ characteristic quantitative pattern of gene products would provide sensitive enough indictors of the metabolic lesions and of the aberrant aspects of differentiation that were responsible for them. In both the presence and absence of detectable morphologic abnormalities, the study of enzymes, this most varied and largest class of specific chemical constituents, would greatly extend the resolving power of the usual diagnostic procedures postmortem.

\section{Speculation}

The sequence in which different enzymes approach their adult concentration in human liver closely resembles that in rat liver.
This suggests that the mechanisms responsible for the schedule of gene expression must also be analogous: the synthesis of specific groups of enzymes at each corresponding critical period is regulated by the same hormones in both species. Hence, the "enzyme pathology" of infant livers not only specifies basic metabolic lesions: aided by observations on the rat model, it could also identify the age of onset and the kind of aberrations in the fetal environment which initiated the lesions.

Long before the elucidation of the nature of gene action, Needham (1931) (48) perceived the central importance of the changing profile of specific proteins in embryonic development. He felt, however, that proper use of enzymes as indicators of tissue differentiation would have to await the availability of less ambiguous and more sensitive assay technicues. The ambiguity, namely, whether the activity assays are supposed to reflect the catalytic efficiency or the amounts of enzymes, began to be resolved in the 1950's. After Knox's discovery of adaptive enzyme synthesis in mammalian tissues (35), methods were developed for measuring changes in the amounts of enzymes (the primary regulators of physiologic function) as distinct from fluctuations in their activity (a superimposed fine control). It soon became apparent that even during late fetal and postnatal development the differentiation of tissue functions depended to a large extent on the synthesis of enzymes de novo and not merely on the activation of those already present in the embryo $(30,38$, 49). Indications were obtained that in man, too (40), some hepatic enzymes may still be absent at term. A certain flexibility in time schedule was first suggested by experiments in which the synthesis of a hepatic enzyme was enhanced or delayed by preor postmature delivery $(8,49)$, and that of an intestinal enzyme by changes in endocrine status (46). The relevance of these early findings to the frequently observed functional deficiencies in apparently normal newborn infants (9) was one stimulus for extensive biochemical research on tissues of developing mammals. These confirmed that the enzymic profiles that are to distinguish mature tissues from one another continue to evolve and to undergo drastic changes long after these tissues have become morphologically distinct. During this postembryonic de- 